\title{
IMPACT OF METEOROLOGICAL FACTORS ON SUICIDE ATTEMPTS AND COMPLETED SUICIDES IN CROATIA, OSIJEK-BARANJA COUNTY
}

\author{
Boris Dumenčić $^{1,2}$, Jasmina Rajc ${ }^{1,2}$, Ksenija Marjanović ${ }^{1,2}$, Ivan Požgain ${ }^{1,3}$ \& Dino Pavoković ${ }^{4}$ \\ ${ }^{I}$ Faculty of Medicine, University of Osijek, Osijek, Croatia \\ ${ }^{2}$ Clinical Department of Pathology and Forensic Medicine, Osijek University Hospital, Osijek, Croatia \\ ${ }^{3}$ Clinical Department of Psychiatry, Osijek University Hospital, Osijek, Croatia \\ ${ }^{4}$ General Hospital Virovitica, Virovitica, Croatia
}

received: 29.1.2019;

revised: 25.4.2019;

accepted: 26.5.2019

\section{SUMMARY}

Backgraund: Significant changes in the values of temperature, pressure, humidity and cloud cover can participate in the human behaviour including the mood disorders (especially depression and bipolar disorders) which can trigger suicidal ideas or their realization. The aim of this study is to estimate the connection between the aforesaid weather changes and a committed suicide along with the suicide attempts.

Subjects and methods: We conducted a retrospective study in Osijek-Baranja County in the period from 2000 to 2011. Meteorological, demographic and epidemiological analysis was performed on 569 suicides and 478 suicide attempts (total of 1047 events). We analyzed the values of the above-mentioned meteorological parameters at the exact time when the event had happened, as well as three days before the event and one day after the event, comparing it with the monthly mean values.

Results: The results showed that the changes of temperature and pressure were significantly related with the suicides i.e. suicide attempts in general, while by separating genders, a connection with all examined meteorological factors was found by woman whereas men expressed significance only in the matter of temperature changes.

Conclusions: Despite the fact that suicidality is caused by numerous factors, this study confirms that a sudden change of weather in the days preceding the suicide can be a trigger to suicidal behaviour. The study also suggests that in the matter of suicidal behaviour, female population is more susceptible to sudden weather changes.

Key words: suicide - suicide attempt - meteorological parameters

$$
* * * * *
$$

\section{INTRODUCTION}

Both suicide attempts and completed suicides still represent a great worldwide public health problem and an ongoing healthcare issue. The World Health Organization estimates a number of 10-20 million suicide attempts and one million completed suicides each year (WHO \& Mental and Behavioural Team 1999). Generally, death by suicide is among ten leading causes of death, taking the third place among people at the age of 15-44, and the second place as the most common cause of death in population aged 15-19 (Patton et al. 2009)

Additionally, previous epidemiologic studies have estimated that about $5 \%$ of the population has attempted suicide at least once (Chen et al. 1996). According to gender ratio, male population has a greater ratio of suicides $(3: 1)$, while on the other hand, female population is more prone to suicidal attempts (Marčinko 2011). These gender differences are even more pronounced in some European countries such as Greece and Ireland, where suicidal ratio is $6: 1$ in favor to male population (Chishti et al. 2018).

Suicide rates vary from 13-42 suicides per 100.000 persons registered in Eastern Europe, to less than 10 suicides per 100.00 persons in "Latin Europe" (Greece, Spain, Italy) and Latin America (Rinmer et al. 2013).
$46 \%$ of all suicides are registered in Western Pacific Region and even 30\% are counted in China and Japan (Wasserman \& Wasserman 2013). Suicide rate in Croatian in the year 2012 was 18.1 per 100.000 people.

Rural areas around the world display higher rates of suicide than urban areas (Dudley et al. 1998). Suicide rates generally increase with age although in some countries the second spike was registered by people at the age of 15-24 (Krug et al. 2002). Along with many economic, socio- cultural, religious and geographic factors, there is a great connection between suicide behavior and climatic variables such as temperature, atmospheric pressure, seasonality, humidity, sunlight, etc. (Deisenhammer 2003). Also, a great number of studies point out mental disorders such as bipolar disorder (Mert et al. 2015) major depression (Oquendo et al. 2002), alcohol or other substance use disorders (Preuss et al. 2003), hopelessness (Maser et al. 2002), separation or loss (Borg et al. 1982) and anger (Goldney et al. 1997) as predictors for the suicidal behavior. Different kinds of climate changes affect mental condition by influencing physical health or physical and social environment, therefore there are current concerns that the meteorological changes have been prominent in the last few decades (e.g. global warming) and could lead to an increase of mental disorder as well as suicide rates (Ruuhela et al. 2003). 
Despite the established influence of the meteorological factors on human behavior and mental health, the most findings in the previous "Climate-Suicide" researches are not consistent, sometimes even contradictory (Dixon et al. 2009). These differences can be partially explained considering a different geographic location, seasonality, a small study area, different statistical methods, a small number of cases or short periods of time, but they all seem to lack an exact method used for evaluation and connection of a certain meteorological parameter with the event, along with the selection of the median monthly, weekly or daily values. Most of the published researches compared a median daily value and the quartiles of the both minimum or maximum temperature values on the exact day when the event happened (Töro et al. 2009), following the presumption that the troublesome weather condition has occurred at the day the event had happened, or on the other hand, exploring the potential cumulative effect resulting with the accumulation of certain uninterrupted climatic conditions and their impact on suicidal behavior.

However, in our investigation we presumed that the continuous weather conditions, even unfavorable ones, are not as important as sudden changes in weather parameters that took place a few days before the event, suggesting that these climatic changes are the ones that have crucial impact on the human behavior and suicidal rates.

\section{SUBJECTS AND METHODS}

\section{Suicide and suicide attempts data}

This study was designed as retrospective and included 569 suicides and 478 suicide attempts registered in Osijek-Baranja County from January 1, 2000 to December 31, 2011. Conducted suicide and suicide attempt data was collected in cooperation with the Police Department of Osijek-Baranja County by using their investigation records. We excluded cases that were not proven to be suicides beyond every doubt, and in regard to the suicidal attempts, we included only violent cases that were reported and investigated by the police.

\section{Meteorological variables}

Daily meteorological data was collected in cooperation with the Department of aeronautical meteorology of Croatian control, at the Airport Klisa - Osijek, where the values of temperature, atmospheric pressure, air humidity and cloudiness were measured every day during the mentioned period of the 11 years by using the appropriate equipment. The measurements were performed repeatedly at the exact same time during the day (07.00 am, $02.00 \mathrm{pm}$ and $09.00 \mathrm{pm})$ and were recorded in climatologically diaries.
The values where measured in following units: temperature in ${ }^{\circ} \mathrm{C}$, atmospheric pressure in $\mathrm{hPa}$, air humidity in $\%$, and the cloudiness in the tenths of overall sky coverage.

The meteorological data of aforementioned measuring site was representative for all parts of the County, taking into consideration the small surface area of Osijek-Baranja County $\left(4,125 \mathrm{~km}^{2}\right)$ and uniform lowland geographical structure.

By using the data from the investigation reports made by the Police Department of Osijek-Baranja County, we were able to approximate the time of the day at which the event had occurred and accordingly select the meteorological value (measured at $07.00 \mathrm{am}$, $02.00 \mathrm{pm}$ or $09.00 \mathrm{pm}$ ) that was closest to an estimated hour of the event. That kind of systematization and event categorization precisely associates the event itself with the measured values of meteorological parameters that had occurred at a specific part of a day. Subsequently, those values were compared with the meteorological parameters measured in the same way 24, 48 and 72 hours prior to the event, 24 hours after the event, along with the mean monthly values.

\section{Statistical analysis}

Data from the individual reports were collected in a unique digital base using computer program Microsoft Excel 2010, Micosoft Inc. (licence MFOS). Statistical data analysis was made on a personal computer using statistic software Statictica 11.0 StatSoftlnc (licence MFOS).

For the comparison of two dependent samples we used Wilcoxon signet-rank test, while Friedman test was used for the comparison of multiple samples. For absolute comparison of the categorical variables we performed a Chi-square test.

Numerical data and scores were shown by median and interquartile range, whereas categorical data was presented as absolute and relative frequencies. The critical level of statistical significance was accepted for $\mathrm{p}<0.05$.

\section{RESULTS}

This retrospective study included 478 suicides and 569 suicide attempts recorded in the period from 2000 to 2011. Overall, 329 (31.4\%) were female and 718 (68.6\%) male. The median age was 39 with interquartile range from 20 till 49 year of age. 14.4\% of them left a farewell letter, most of them were married (49\%) and $48 \%$ with high school education. In $37 \%$ of victims, we found an evidence of alcoholism or other mental disorder, while in $30 \%$ of cases there were no obvious reasons or motives for a suicidal behavior. The most frequent method was hanging $(37 \%)$ and the suicides or suicide attempts mostly took place indoors, at home (38\%) (Table 1). 
Table 1. Epidemiological characteristics

\begin{tabular}{|c|c|c|}
\hline Parameters & Categories & No $(\%)$ \\
\hline Gender & $\begin{array}{l}\text { Male } \\
\text { Female }\end{array}$ & $\begin{array}{l}718(68.6) \\
329(31.4)\end{array}$ \\
\hline Attempt/Suicide & $\begin{array}{l}\text { Attempt } \\
\text { Suicide }\end{array}$ & $\begin{array}{l}569(54.3) \\
478(45.7)\end{array}$ \\
\hline Farewell letter & $\begin{array}{l}\text { Yes } \\
\text { No }\end{array}$ & $\begin{array}{l}109(14.4) \\
648(85.6)\end{array}$ \\
\hline Location & $\begin{array}{l}\text { Indoor } \\
\text { Back yard } \\
\text { Shed, attic, garage } \\
\text { Forrest, train track or parking place } \\
\text { Other }\end{array}$ & $\begin{array}{l}220(37.7) \\
103(17.7) \\
149(25.6) \\
103(17.7) \\
8(1.4)\end{array}$ \\
\hline Education & $\begin{array}{l}\text { Without education } \\
\text { Elementary school } \\
\text { High school } \\
\text { College } \\
\text { Unknown }\end{array}$ & $\begin{array}{c}16(3.6) \\
182(40.9) \\
215(48.3) \\
26(5.8) \\
6(1.3)\end{array}$ \\
\hline Motive & $\begin{array}{l}\text { Alcoholism } \\
\text { Mental disorders } \\
\text { Family disputes } \\
\text { Life stress (unemployment, death in the family, love affairs) } \\
\text { Poverty } \\
\text { Old age } \\
\text { Physical illness } \\
\text { Unknown }\end{array}$ & $\begin{aligned} 69 & (9.4) \\
199 & (27.2) \\
69 & (9.4) \\
29 & (4.0) \\
13 & (1.8) \\
59 & (8.1) \\
72 & (9.8) \\
221 & (30.2)\end{aligned}$ \\
\hline Methods & $\begin{array}{l}\text { Jumping from a high place } \\
\text { Explosive device } \\
\text { Asphyxia } \\
\text { Hanging } \\
\text { Poisoning } \\
\text { Firearms } \\
\text { Stubbing and self cutting } \\
\text { Drowning }\end{array}$ & $\begin{array}{c}45(6.0) \\
18(2.4) \\
10(1.3) \\
274(36.6) \\
136(18.2) \\
68(9.1) \\
130(17.4) \\
68(9.1)\end{array}$ \\
\hline Marital status & $\begin{array}{l}\text { Child } \\
\text { Partnership } \\
\text { Marriage } \\
\text { Unmarried } \\
\text { Divorced } \\
\text { Widower } \\
\text { Unknown }\end{array}$ & $\begin{array}{c}6(0.8) \\
12(1.6) \\
361(49.0) \\
217(29.4) \\
25(3.4) \\
40(5.4) \\
76(10.3)\end{array}$ \\
\hline
\end{tabular}

Table 2. Difference regarding gender in attempts and committed suicides

\begin{tabular}{lcccr}
\hline & \multicolumn{2}{c}{ No $(\%)$} & & P* \\
Male & Female & & 569 \\
Attempts & $356(49.6)$ & $213(64.7)$ & $<0.01$ & 478 \\
Committed suicides & $362(50.4)$ & $116(35.3)$ & & 1047 \\
Total & $718(100.0)$ & $329(100.0)$ & & \\
\hline
\end{tabular}

*Chi-square test

There is significant difference in gender regarding attempts and committing suicides $(\mathrm{p}<0.001$; Chi-square test), as every second male committed suicide while only every third woman committed suicide (Table 2).

Considering a number of suicides or suicide attempts within a peculiar year, month, day of the week or even a part of the day, we found no spikes with almost equal distribution of the events. But, assessing season cycles of the year, we found a statistically higher rate of suicide or suicide attempts in warmer months (May, June, July and August) (43\%), as opposed to colder part of the year (November, December, January and February) $(28 \%)$ and the transition period (March, April, September and October) (30\%) (Figure 1). 
Table 3. Meteorological changes in five days along with mean monthly values compared with the day of the event both genders (Wilcoxon signet-rank test)

\begin{tabular}{lcccc}
\hline \multirow{2}{*}{ Time of the event } & Temperature $\left({ }^{\circ} \mathrm{C}\right)$ & Pressure $(\mathrm{hPa})$ & Humidity $(\%)$ & Clodiness $(*)$ \\
& $\mathrm{Me}(25-75 \%)$ & $\mathrm{Me}(25-75 \%)$ & $\mathrm{Me}(25-75 \%)$ & Me $(25-75 \%)$ \\
\hline 72 h prior & $14.2(6.1-21.0)$ & $1006.0(1001.2-1010.1)$ & $77.0(56.0-90.0)$ & $5.0(0.0-9.0)$ \\
& $p=0.009$ & $\mathrm{p}=0.057$ & $\mathrm{p}=0.602$ & $7=0.107$ \\
48 h prior & $14.3(6.5-21.1)$ & $1005.9(1001.8-1009.9)$ & $78.0(54.0-90.0)$ & $5.0(1.0-9.0)$ \\
& $p=0.042$ & $p=0.045$ & $\mathrm{p}=0.625$ & $\mathrm{p}=0.168$ \\
24 h prior & $14.5(6.7-21.1)$ & $1005.5(1001.8-1010.2)$ & $78.0(52.0-90.0)$ & $5.0(1.0-9.0)$ \\
& $p=0.028$ & $p=0.003$ & $\mathrm{p}=0.833$ & $\mathrm{p}=0.099$ \\
Day of the event & $14.5(6.3-21.0)$ & $1005.4(1001.2-1009.6)$ & $77.0(55.0-91.0)$ & $5.0(1.0-9.0)$ \\
24 h after & $14.7(6.4-21.2)$ & $1005.4(1001.2-1009.6)$ & $78.0(53.0-91.0)$ & $5.0(1.0-9.0)$ \\
& $\mathrm{p}=0.392$ & $\mathrm{p}=0.251$ & $\mathrm{p}=0.416$ & $\mathrm{p}=0.421$ \\
Mean monthly value & $14.7(6.4-21.2)$ & $1005.6(1003.5-1007.6)$ & $76.2(58.2-86.2)$ & $5.0(1.0-9.0)$ \\
& $p=0.001$ & $\mathrm{p}=0.797$ & $\mathrm{p}=0.203$ & $\mathrm{p}=0.737$ \\
\hline
\end{tabular}

*measured in the tenths of the sky covered by clouds

Table 4. Meteorological values in five days along with mean monthly values compared with the day of the event females (Wilcoxon signet-rank test)

\begin{tabular}{|c|c|c|c|c|}
\hline Time of the event & $\begin{array}{c}\text { Temperature }\left({ }^{\circ} \mathrm{C}\right) \\
\text { Me }(25-75 \%)\end{array}$ & $\begin{array}{l}\text { Pressure }(\mathrm{hPa}) \\
\mathrm{Me}(25-75 \%)\end{array}$ & $\begin{array}{l}\text { Humidity }(\%) \\
\text { Me }(25-75 \%)\end{array}$ & $\begin{array}{l}\text { Clodiness }(*) \\
\operatorname{Me}(25-75 \%)\end{array}$ \\
\hline $72 \mathrm{~h}$ prior & $\begin{array}{c}14.0(5.2-21.1) \\
p=0.016\end{array}$ & $\begin{array}{c}1006.2(1001.4-1010.2) \\
p=0.052\end{array}$ & $\begin{array}{c}77.0(50.0-91.0) \\
p=0.295\end{array}$ & $\begin{array}{c}4.0(0.0-9.0) \\
\mathrm{p}=0.122\end{array}$ \\
\hline $48 \mathrm{~h}$ prior & $\begin{array}{c}14.7(6.0-21.2) \\
\mathrm{p}=0.238\end{array}$ & $\begin{array}{c}1006.4(1001.8-1011.0) \\
p=0.011\end{array}$ & $\begin{array}{c}74.0(46.0-90.0) \\
\mathrm{p}=0.065\end{array}$ & $\begin{array}{c}4.0(0.0-9.0) \\
p=0.059\end{array}$ \\
\hline $24 \mathrm{~h}$ prior & $\begin{array}{c}14.4(6.7-21.8) \\
p=0.807\end{array}$ & $\begin{array}{c}1005.7(1001.8-1010.9) \\
p=0.010\end{array}$ & $\begin{array}{c}76.0(47.0-91.0) \\
p=0.034\end{array}$ & $\begin{array}{c}5.0(1.0-9.0) \\
p=0.021\end{array}$ \\
\hline Day of the event & $14.2(6.2-21.7)$ & $1005.3(1001.8-1010.0)$ & $80.0(50.3-91.0)$ & $5.0(1.0-9.0)$ \\
\hline $24 \mathrm{~h}$ after & $\begin{array}{l}14.7(6.0-21.6) \\
\quad p=0.470\end{array}$ & $\begin{array}{c}1005.5(1001.4-1010.1) \\
p=0.961\end{array}$ & $\begin{array}{c}79.0(50.0-92.0) \\
\mathrm{p}=0.361\end{array}$ & $\begin{array}{c}6.0(1.0-9.0) \\
p=0.283\end{array}$ \\
\hline Mean monthly value & $\begin{array}{c}14.7(6.1-20.5) \\
p=0.112\end{array}$ & $\begin{array}{c}1005.6(1003.5-1007.8) \\
p=0.515\end{array}$ & $\begin{array}{c}75.5(53.1-86.5) \\
p=0.464\end{array}$ & $\begin{array}{c}5.0(3.9-6.1) \\
\mathrm{p}=0.140\end{array}$ \\
\hline
\end{tabular}

*measured in the tenths of the sky covered by clouds

Table 5. Meteorological changes in five days along with mean monthly values in relation to the day of the event - males (Wilcoxon signet-rank test)

\begin{tabular}{lcccc}
\hline \multirow{2}{*}{ Time of the event } & Temperature $\left({ }^{\circ} \mathrm{C}\right)$ & Pressure $(\mathrm{hPa})$ & Humidity $(\%)$ & $\begin{array}{c}\text { Clodiness }(*) \\
\text { Me }(25-75 \%)\end{array}$ \\
\hline 72 h prior & Me $(25-75 \%)$ & $\mathrm{Me}(25-75 \%)$ & $\mathrm{Me}(25-75 \%)$ & $4.0(0.0-9.0)$ \\
& $14.3(6.4-21.0)$ & $1005.8(1001.2-1009.9)$ & $78.0(57.0-90.0)$ & $\mathrm{p}=0.356$ \\
48 h prior & $\mathrm{p}=0.123$ & $\mathrm{p}=0.334$ & $\mathrm{p}=0.188$ & $4.0(0.0-9.0)$ \\
& $14.1(6.5-21.0)$ & $1005.6(1001.7-1009.6)$ & $79.0(56.0-90.0)$ & $\mathrm{p}=0.650$ \\
24 h prior & $\mathrm{p}=0.087$ & $\mathrm{p}=0.477$ & $\mathrm{p}=0.068$ & $5.0(1.0-9.0)$ \\
& $14.5(6.7-20.7)$ & $1005.4(1001.8-1009.9)$ & $78.0(55.0-90.0)$ & $\mathrm{p}=0.637$ \\
Day of the event & $p=0.014$ & $\mathrm{p}=0.077$ & $\mathrm{p}=0.103$ & $5.0(1.0-9.0)$ \\
24 h after & $14.5(6.3-20.8)$ & $1005.4(1001.4-1009.3)$ & $77.0(56.0-90.0)$ & $6.0(1.0-9.0)$ \\
& $14.7(6.5-21.2)$ & $1005.4(1001.2-1009.3)$ & $78.0(53.0-91.0)$ & $\mathrm{p}=0.098$ \\
Mean monthly value & $14.7(5.5-20.6)$ & $1005.6(1003.5-1007.6)$ & $76.4(59.2-85.9)$ & $5.0(3.9-6.1)$ \\
& $p=0.003$ & $\mathrm{p}=0.913$ & $p=0.041$ & $\mathrm{p}=0.557$ \\
\hline
\end{tabular}

*measured in the tenths of the sky covered by clouds

With regard to the meteorological conditions, by estimating temperature values in a period of five days (three days before the event, day of the event and one day after) we found a statistically significant temperature changes (Friedman test, $\mathrm{p}>0.001$ ) and changes of the atmospheric pressure (Friedman test, $\mathrm{p}=0.003$ ).
Additionally, we proved a statistically significant connection comparing mean monthly temperature values and temperature values measured 72, 48 and 24 hours before the event, with the temperature measured on the exact day when the event happened. At the same time no significant connection was found between tempera- 
ture values on the day that the event had happened and a day after. Furthermore the values of the atmospheric pressure measured 48 and 24 hours before the event were again statistically significant in regard to the exact day of the event. No such connection was found in the matter of the humidity or cloudiness (Table 3).

By separating all the subjects by gender, we found that the women are more prone to commit or attempt a suicide in the afternoon, and much less in the forenoon or during the night ( $\mathrm{p}=0.044$; Chi-square test), as opposed to the male population that showed no statistically significant predilection in regard to a certain part of the day ( $\mathrm{p}=0.826$; Chi-square test).

Furthermore, in female population alone, we found a statistically significant connection considering all the examined meteorological conditions (temperature, atmospheric pressure, humidity and cloudiness). Regarding temperature and atmospheric pressure changes in a period of five days for female population, we found statistically significant changes considering the whole period of five days (three days before event, day of the event and one day after, Friedman test; $\mathrm{p}=0.008$, and $\mathrm{p}=0.002$ ), however these changes were not significantly associated with the matter of humidity and cloudiness. Also, in women we established a positive correlation between the values measured 72,48 and 24 hours before the event and the value measured on the exact day when the event happened, in regard to all examined meteorological parameters (temperature, atmospheric pressure, cloudiness, and humidity) (Table 4). Interestingly, in men, by applying the same methods, only temperature changes during the period of five days (Friedman test; $\mathrm{p}=0.005$ ), as well as 24 hours before the event were found as significant (Table 5).

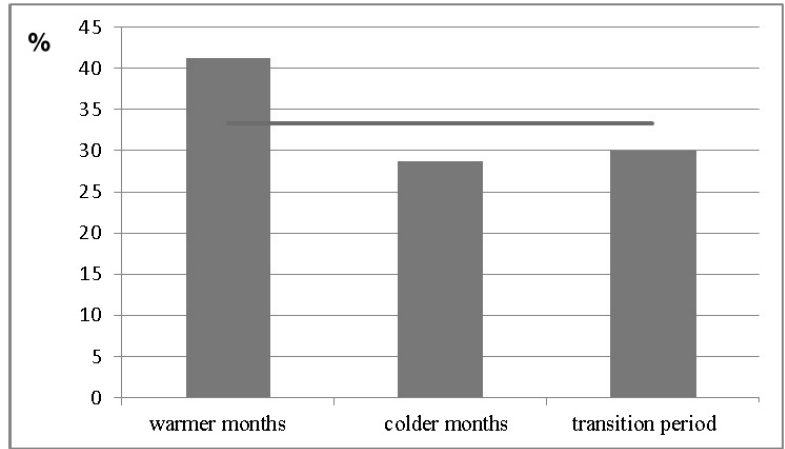

Figure 1. Higher rate of the suicide and suicide attempts in warmer months (May, June, July and August)

\section{DISCUSSION}

It is a well-known fact that the meteorological circumstances have an influence on the physical and psychological health of humans and make an impact on human behaviour (Carleton 2017). In addition, a greater number of suicides can occur in a specific set of meteorological conditions, regardless the geographic location on Earth and specific climatic variables.
Nevertheless, in our research we explored a quite small geographic area with approximately equal climatic characteristics.

Regarding the influence of the temperature changes, some authors have found an increase in the number of suicides when temperatures are colder (Linkowski et al. 1992, Souêtre et al. 1990) whereas some authors have published the opposite results (Maes et al. 1994).

In our research we observed a slight temperature increase in the days preceding the event, confirming some previous findings related to stressful effect of temperature increase on unadapted organism. For example, Volpe et al. proved that suicide rates are connected with a sudden increase of temperature registered at the end of spring or summer, and furthermore, actualization of some mental disorders such as psychosis positively correlates with a number of sunny hours (Volpe et al. 2008). An exact pathophysiological mechanism of how atmospheric temperature can impact human organism is still unknown, but it is obvious that a sudden temperature increase along with the increased humidity can indispose a body heat evaporation and induct a thermoregulational disbalance.

Despite the little consistency in the previous results of various climate-suicide researches, one of the most consistent finding is a seasonal distribution with the most common peak occurring in spring, or early summer, so called "spring fever" (Chew \& McCleary 1995). This phenomenon is specially observed on teenagers or elderly that are suffering from chronic illnesses. It seems that during the colder, darker and shorter days when everybody is in the blue mood, it is easier to cope with the depression blaming the weather circumstances and expecting to feel better when the spring arrives. These findings are partly consistent with a peak of suicides and suicide attempts in summer months, mostly in August, that we observed in our research (Figure 1).

Additionally by exploring a tight relationship between temperatures and seasons, a great study has been conducted in India, where one fifth of global suicides occurs (Carleton 1990). According to this study, over the last 20 years, suicide rates have doubled due to the fluctuations in temperature, foremost due to temperature increase, in the way that for temperatures above $20^{\circ} \mathrm{C}$, a $1^{\circ} \mathrm{C}$ increase in a single day causes about 70 more suicides. However, this phenomenon has been documented only during the agricultural growing season.

Air humidity is usually examined together with the other meteorological parameters, especially with the temperature, considering their cumulative effect on body temperature regulation that can produce a thermoregulatory stress.

Töro et al. (2009) examined a combination of warmer weather and the lower air humidity known as dry anticyclone and established a positive connection of such weather conditions with the suicide rates in Hungary. 
However, in spite of the value of the average daily temperatures on the exact day of the event, whether it was high or low, our investigation has proved that the changes of the temperature values in the days preceding the event in regard to a day when the event happened is crucial, and in fact, these changes of temperature values, that happen in the period of three days before the event, obviously participate in a decision of committing a suicide. Also, we found no statistically significant changes of the temperature values between the day when the event happened and a day after.

Very similar results have been discovered in the matter of atmospheric pressure in which significant changes of values on days before the event have been recorded, as opposed to the day after the event.

Sudden weather changes such as perturbation of atmospheric pressure clearly lead to violation of basic mental and physiologic functions in humans (Didyk et al. 2010, Delyukov et al. 1999). Schory et al. 2018 presented a positive connection of all forms of violent behavior along with the more frequent admittance in psychic hospital wards during the low atmospheric pressure in the USA, while Ruuhela et al. 2009, during the investigation conducted in Finland, found that the air pressure has an effect on a suicidal behavior, especially suicide attempts with more violent methods, but within male population this impact is apparent during the lower air pressure $(<1005 \mathrm{hPa})$, while females were more sensitive on higher pressure $(>1020 \mathrm{hPa})$. Falak et al. 2019. presented that increase of $10 \mathrm{hPa}$ in air pressure from 7.00 am to $2.00 \mathrm{pm}$ was accompanied by a $78.17 \%$ decrease in emergency admission odds and this decrease could be as little $0.3 \%$ or high $95.2 \%$ confidence interval.

On the contrary, we have not proved similar connection for the cloudiness and humidity, without statistically significant changes in the days preceding the event.

Interestingly, by investigating meteorological changes in a subgroup of female population, we found the suicides and the suicide attempts to be correlated with all examined meteorological factors (temperature, atmospheric pressure, humidity and cloudiness), but when we isolated the male population, we found connection with temperature changes only, suggesting that women are more sensitive to various meteorological changes. In the investigated period of ten years in Turkey, Asirdizer et al 2018. also found that high altitude above $1500 \mathrm{~m}$, winter median temperature lower than $-10^{\circ} \mathrm{C}$ and hared temperature changes above $25^{\circ} \mathrm{C}$ between winter and summer of settlements were important factors regarding female suicide rates. These findings can be partly explained considering a hormonally determined lower perspiration within female population, wherefore they could be more prone to the previously mentioned thermoregulatory distress. Also, some authors connect this fact with much higher rates of suicide attempts in female population as opposed to the male ones, which are well documented in the literature (Mościcki 1994, Tsirigotis et al. 2011). Our study shows that within the total number of suicide attempts and committed suicides in female population, a $64.7 \%$ of them attempted suicide as oppose to the male gender who had $49.6 \%$ attempts. Significant prevalence of males in our study $(68.5 \%)$ can also go along with the fact that only violent, serious cases, investigated by police were included in this trial, whereas women are more prone to suicidal attempts, often a mild ones without serious life threatening medical conditions.

The limitations of the study are mainly related to a quite small geographic area, while similar researches should be performed at multiple locations to avoid possible anomalous local variables.

Also, we can raise a question regarding the influence of the air conditioning in closed spaces, that become a great part of our everyday living. A further investigation should be performed to see weather this mentioned meteorological changes have the same effect on the individuals who spent a lot of time in a such controlled environment.

Conclusively, we found significant changes in weather conditions mainly regarding temperature and the atmosphere pressure, registered in a period of a few days before the event. The change of weather conditions on the days preceding the event could be of a much more importance than the values registered at the same day of the event, even along with the comparison to the mean monthly values.

Furthermore, we must consider the fact that each meteorological parameter can also change during the day, having the daily cycle, in which, for example, humidity is highest in the morning or evening as opposed to temperature values. The unfavorable change that can happen during the day such as sudden decrease in temperature and pressure along with an increase of humidity can potentially impact the human mood and be a trigger for suicide ideas.

So, in the future suicide-climate researches, we can measure and include the meteorological conditions that preceded the event, including the change of meteorological conditions at the same day, and therefore by grouping suicides or suicide attempts in specific lines of meteorological changes we could be able to single out stressful and potentially suicidal weather changes.

\section{CONCLUSIONS}

This study included 569 suicides and 478 violent suicide attempts and demonstrates the correlation between suicides and suicide attempts with a changes in atmospheric temperature, pressure, humidity and cloudiness.

We found a statistically significant temperature changes and changes of the atmospheric pressure in a period of five days (three days before the event, day of 
the event and one day after). Additionally, we proved a statistically significant connection comparing mean monthly temperature values and temperature values measured 72, 48 and 24 hours before the event, with the temperature measured on the exact day when the event happened. At the same time no significant connection was found between temperature values on the day that the event had happened and a day after. Furthermore the values of the atmospheric pressure measured 48 and 24 hours before the event were again statistically significant in regard to the exact day of the event. No such connection was found in the matter of the humidity or cloudiness.

Furthermore, in female population alone, we found a statistically significant connection considering all the examined meteorological conditions. Regarding temperature and atmospheric pressure changes in a period of five days for female population, we found statistically significant changes considering the whole period of five days, however these changes were not significantly associated with the matter of humidity and cloudiness. Also, in women we established a positive correlation between the values measured 72, 48 and 24 hours before the event and the value measured on the exact day when the event happened, in regard to all examined meteorological parameters. Interestingly, in men, by applying the same methods, only temperature changes during the period of five days, as well as 24 hours before the event were found as significant.

The results of this study suggest that women are more sensitive to sudden weather changes and that may be the reason they are more prone to attempting suicide than men. The causes of suicide are multifactorial, and this study suggests that sudden weather changes may be one of the factors that trigger a suicide.

\section{Acknowledgements: None.}

\section{Conflict of interest: None to declare.}

\section{Contribution of individual authors:}

Boris Dumenčić conceived the presented idea, developed the theory and performed the computations, conducted and analysed data acquisition process, and discussed results with all authors.

Jasmina Rajc searched literature, analysed and interpreted data, and took the lead in writing the manuscript.

Ksenija Marjanović searched literature, analysed and interpreted data and drafted the manuscript.

Ivan Požgain provided critical feedback and helped shape the research, analysed and drafted of manuscript.

Dino Pavoković conducted data acquisition process, designed data acquisition and statistical analysis.

\section{References}

1. Asirdizer M, Kartal E, Etli Y, Tatlisumak E, Gumus $O$, Hekimoglu $Y$ et al.: The effect of altitude and climate on the suicide rates in Turkey. J Forensic Leg Med 2018; 54:91-95

2. Borg SE \& Ståhl M: Prediction of suicide. A prospective study of suicides and controls among psychiatric patients. Acta Psychiatr Scand 1982; 65:221-32

3. Carleton TA: Crop-damaging temperatures increase suicide rates in India. Proc Natl Acad Sci 2017; 114:8746-51

4. Chen $Y W \&$ Dilsaver SC: Lifetime rates of suicide attempts among subjects with bipolar and unipolar disorders relative to subjects with other Axis I disorders. Biol Psychiatry 1996; 39:896-9

5. Chew KS \& McCleary R: The spring peak in suicides: a cross-national analysis. Soc Sci Med 1995;40:223-30

6. Chishti P, Roulston C, Corcoran P, Williamson E, Elgie R, Renberg E: Final report of the european review of suicide and violence epidemiology (eurosave) project, 2018

7. Deisenhammer EA: Weather and suicide: the present state of knowledge on the association of meteorological factors with suicidal behaviour. Acta Psychiatr Scand 2003; 108:402-9

8. Delyukov AA \& Didyk L: The effects of extra-lowfrequency atmospheric pressure oscillations on human mental activity. Int J Biometeorol 1999; 43:31-7

9. Didyk LA, Gorgo YP, Dirckx JJJ, Semenova IA, Didyk NP, Gorlov DS: The effects of slight atmospheric pressure fluctuations on the occurrence of emergency transport due to suicidal injuries. Health 2010; 5:448-453

10. Dixon G \& Kalkstein JA: Climate-Suicide Relationships: A Research Problem in Need of Geographic Methods and Cross-Disciplinary Perspectives. Geography Compass 3 2009; $1-14$

11. Dudley MJ, Kelk NJ, Florio TM, Howard JP, Waters BG: Suicide among young Australians, 1964-1993: an interstate comparison of metropolitan and rural trends. Med $J$ 1998; 169:77-80

12. Falak H, Silić A, Golub M, Perišić A, Košec A, Udovičić M: The inflenuce of meteorological parameters on intentional self-harm emergency admissions, Psychiatr Danub 2019; 31 (in press)

13. Goldney R, Winefield A, Saebel J, Winefield H, Tiggeman $M$ : Anger, suicidal ideation, and attempted suicide a prospective study. Compr Psychiatry 1997; 38:264-8

14. Krug EG, Mercy JA, Dahlberg LL, Zwi AB: The world report on violence and health. Lancet 2002; 5:1083-8

15. Linkowski P, Martin F \& De Maertelaer V: Effect of some climatic factors on violent and non-violent suicides in Belgium. J Affect Disord 1992; 25:161-6

16. Maes M, De Meyer F, Thompson P, Peeters D, Cosyns P: Synchronized annual rhythms in violent suicide rate, ambient temperature and the light-dark span. Acta Psychiatr Scand 1994; 90:391-6

17. Marčinko D: Suicidologija. Medicinska naklada, Zagreb, 2011

18. Maser JD, Akiskal HS, Schettler P, Scheftner W, Mueller $T$, Endicott J, et al.: Can temperament identify affectively ill patients who engage in lethal or near-lethal suicidal behavior? A 14-year prospective study. Suicide Life Threat Behav 2002; 32:10-32 
19. Mert DG, Kelleci M, Mizrak A, Semiz M \& Demir MO: Factors associated with suicide attempts in patients with bipolar disorder type I. Psychiatr Danub 2015; 236-241

20. Mościcki EK: Gender differences in completed and attempted suicides. Ann Epidemiol 1994; 4:152-8

21. Oquendo MA, Kamali M, Ellis SP, Grunebaum $M F$, Malone KM, Brodsky BS et al.: Adequacy of antidepressant treatment after discharge and the occurrence of suicidal acts in major depression: a prospective study. Am $J$ Psychiatry 2002; 159:1746-51

22. Patton GC, Coffey C, Sawyer SM, Viner RM, Haller DM, Bose $K$ et al.: Global patterns of mortality in young people: a systematic analysis of population health data. Lancet 2009; 374:881-92

23. Preuss UW, Schuckit MA, Smith TL, Danko GP, Bucholz KK, Hesselbrock MN, et al.: Predictors and correlates of suicide attempts over 5 years in 1,237 alcohol-dependent men and women. Am J Psychiatry 2003; 160:56-63

24. Rihmer Z, Gonda X, Kapitany B, Dome P: Suicide in Hungary-epidemiological and clinical perspectives. Ann Gen Psychiatry 2013; 26:12-21

25. Ruuhela R, Hiltunen L, Venäläinen A, Pirinen P, Partonen T: Climate impact on suicide rates in Finland from 1971 to 2003. Int J Biometeorol 2009; 53:167-75
26. Schory TJ, Piecznski N, Nair S, el-Mallakh RS: Barometric pressure, emergency psychiatric visits, and violent acts. Can J Psychiatry 2003; 48:624-7

27. Souetre E, Wehr TA, Douillet P, Darcourt G: Influence of environmental factors on suicidal behavior. Psychiatry Res 1990; 32:253-63

28. Töro K, Dunay G, Bartholy J, Pongrácz R, Kis Z, Keller E: Relationship between suicidal cases and meteorological conditions. J Forensic Leg Med 2009; 6:277-9

29. Tsirigotis K, Gruszczynski $W$ \& Tsirigotis M: Gender differentiation in methods of suicide attempts. Med Sci Monit 2011; 17:65-70

30. Volpe FM, Tavares A \& Del Porto JA: Seasonality of three dimensions of mania,psychosis, aggression and suicidality. J Affect Disord 2008; 108:95-100

31. Wasserman D \& Wasserman C: Global perspective on the magnitude of suicide mortality. Oxford Textbook of Suicidology and Suicide Prevention. Oxford University Press 2011

32. World Health Organization, WHO: Mental and Behavioural Disorders Team. Figures and facts about suicide, 1999.

http://www.who.int/iris/handle/10665/66097
Correspondence:

Boris Dumenčić, $M D, P h D$

Faculty of Medicine, University of Osijek

J. Huttlera 4, 31000 Osijek, Croatia

E-mail:bdumencic29@gmail.com 